\title{
Breast Myoepithelial Tumor
}

National Cancer Institute

\section{Source}

National Cancer Institute. Breast Myoepithelial Tumor. NCI Thesaurus. Code C40389.

A benign or malignant tumor that arises from the breast and originates from or is

composed of myoepithelial cells. Representative examples include

adenomyoepithelioma, myoepitheliosis, and malignant myoepithelioma. 